\title{
Status of a reintroduced population of mountain gazelles Gazella gazella in central Arabia: management lessons from an aridland reintroduction
}

\author{
Kevin M. Dunham
}

\begin{abstract}
Mountain gazelles were reintroduced to central Arabia during 1991-95. Hawtah reserve was searched for gazelles during the 1998-99 winter. Gazelles were seen in one wadi system and their signs were found in several others and on the plateau. Sightings were used to calculate the minimum number of gazelles in the Matham wadi system, which previously held most of the population. During OctoberNovember 1998, the minimum number was 64 per cent less than 4 years earlier. Frequent observation of recent signs in areas where no gazelles were seen suggested that daytime sightings alone were no longer adequate for monitoring this population. The decline in the number of gazelles seen, an increase in their flight distance and an apparent change in their activity
\end{abstract}

patterns were consistent with the rangers' claim that poaching had commonly occurred. Poaching started after reserve management built, without adequate consultation, a new fence that was intended to bar local people from part of the reserve. Management lessons include the need for the following: continued monitoring of reintroduced populations after the initial postrelease phase; long-term dialogue with local people; effective law enforcement; and the management of aridland domestic livestock in ways that prevent interspecific competition for food causing the elimination of wild ungulates.

Keywords Arabia, domestic livestock, gazelles, management, reintroduction.

\section{Introduction}

Populations of desert ungulates in the Middle East and North Africa were depleted during the second half of the twentieth century, mainly by excessive hunting (Thesiger, 1959; Newby, 1990; Cloudsley-Thompson, 1992). Recent reintroductions have tried to reverse these declines (Stanley Price, 1989; Cano et al., 1993). Mountain gazelles Gazella gazella were first reintroduced to central Arabia during 1991 (Dunham et al. 1993). Their numbers increased and initial assessments of the population's prospects were positive. The aim of this survey was to re-assess the status and distribution of the population, and to identify the problems facing it, in order to facilitate its future management. Lessons from this reintroduction are applicable to the planning of other reintroductions in the Middle East and elsewhere.

\section{Study area}

Hawtah Reserve $\left(23^{\circ} 30^{\prime} \mathrm{N}, 46^{\circ} 30^{\prime} \mathrm{E}\right)$ near Hawtah Bani Tamim was established during 1988 by the National Commission for Wildlife Conservation and Development (NCWCD) to protect the last Nubian ibex Capra

Kevin M. Dunham The Zoological Society of London, Regent's Park, London NW1 4RY, UK; Present address: PO Box CH 385, Chisipite, Harare, Zimbabwe. E-mail: faykevin@ecoweb.co.zw

Revised manuscript accepted for publication 13 November 2000 ibex nubiana in central Saudi Arabia. Annual rainfall averaged $112 \mathrm{~mm}$ (SD 51.8, $n=6$, range 18-165). Precipitation occurs mainly during winter and spring (November-April), and summer is dry and hot (mean maximum temperature $>40{ }^{\circ} \mathrm{C}$ ). The reserve covers c. $2000 \mathrm{sq} \mathrm{km}$ (its boundary is not legally defined) and comprises an undulating, stony, limestone plateau, 800 $1100 \mathrm{~m}$ asl, which is deeply incised by wadis where runoff accumulates after rain. Heavy rainfall causes flooding, but water remains in riverbeds for only the days immediately following rain. Plant standing crop is sparse on the plateau, but greater in wadis, where Acacia bushes dominate the vegetation. Local people use the wadis for grazing domestic livestock, collecting firewood, and recreation. Sheep Ovis aries and goats Capra hircus (often in mixed flocks) forage in some wadis, each herd accompanied by a shepherd. They are enclosed in pens at night for protection against predators. In contrast, domestic camels Camelus dromedarius roam the reserve unaccompanied, day and night. All domestic livestock receive water and supplementary food, which their owners bring into the reserve. Wadis Ghaba and Ghafar were fenced to protect the vegetation from camels. Ghaba and Ghafar join to form Matham (Fig. 1a). In this paper, 'wadi Matham' refers to the main, unfenced wadi downstream of this confluence; 'the Matham wadi system' is wadi Matham and all its tributaries, including fenced Ghaba and Ghafar. Occasionally, fences were damaged by floods or 


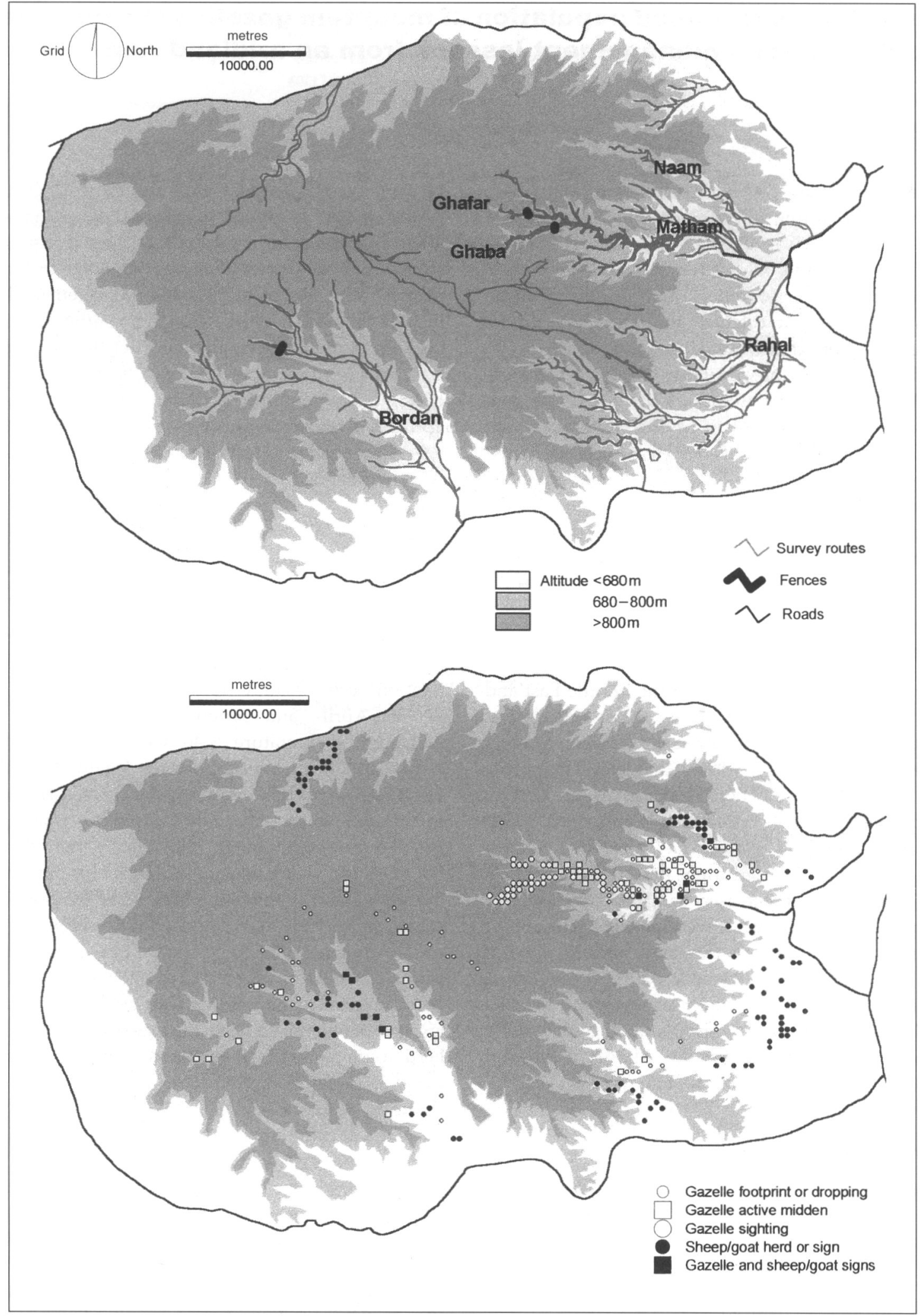

Fig. 1 (a) Hawtah reserve, showing the principal features, the wadis mentioned in the text, the camel-exclusion fences, and survey routes during October 1998-February 1999. The plateau is approximately demarcated by the ground $>800 \mathrm{~m}$ asl. (b) The distribution of mountain gazelles, domestic sheep and goats, and their signs during October 1998-February 1999. Each symbol refers to a $500 \times 500 \mathrm{~m}$ map square. 
people, and camels entered fenced wadis temporarily. A flood-control dam was being built across lower Matham during this survey. There are 10-12 Saudi rangers who live at five stations around the reserve.

Excessive hunting caused the local extinction of mountain gazelles. Their reintroduction involved the release into fenced wadis of 84 animals during 1991-95 (Dunham, 1997). All except two were fitted with tags that allowed them to be individually identified. Their survival rate was high, although wolves Canis lupus and feral dogs Canis familiaris killed some animals. The population was monitored intensively until mid-1995, when there were an estimated 203 gazelles in the reserve, including 177 in the Matham wadi system, with probably some additional animals outside the Matham and Bordan wadi systems (Dunham, 1998c).

\section{Methods}

The reserve was visited on 23 days from 26 October 1998 to 18 February 1999, concentrating on the Matham wadi system. In addition, all major wadis and readily accessible parts of the plateau (Fig. 1a) were surveyed, driving slowly along existing vehicle tracks during daylight, searching for gazelles and their signs (footprints, faecal pellets). This method was similar to that used during 1991-95, when gazelles were less afraid of vehicles than of people walking. Although there are many tracks in the wadis, vehicle access to the plateau is limited by the terrain. Footprints were considered 'recent' if judged to be $<7$ days old, and knowing when traces of rain fell helped with age determination. A dropping was a pile of pellets that was judged to have been produced by one animal during a single defecation. A midden was considered 'active' if there was a urine stain, or black shiny pellets, in its centre. Gazelle signs were often found under Calotropis procera bushes, and therefore searches were concentrated around this vegetation. The sex and age of each gazelle were noted and tags were identified using binoculars or a telescope. Care was taken to avoid recording the same individuals more than once daily and this was facilitated by the linear nature of wadis and the gazelles small ranges (Dunham, 1998a). The locations of gazelles, sheep, goats, large canids (dogs and wolves), and their signs were recorded using a GPS receiver.

During intensive monitoring, the survival of tagged gazelles was known and the total number of gazelles was estimated using mark-resighting techniques (Dunham, 1997). Survival of tagged gazelles since mid-1995 is unknown, however, so these techniques could no longer be used reliably to estimate population number. Instead, the minimum number of gazelles was calculated as the sum of the maximum numbers of individuals in each age/sex class seen on any day, and compared with similar data for 1994. To examine further the changes that occurred after mid-1995, data were used from 1996 to 1998 , when I visited the reserve for reasons often unrelated to gazelles. Changes in age/sex ratios and group composition were assessed using data from visits when I recorded all gazelles seen. Changes in gazelle density in the Matham wadi system were illustrated using data collected along a standard route $17 \mathrm{~km}$ in unfenced Matham and $4 \mathrm{~km}$ in fenced Ghaba) on days when I visited only for the day ( $n=6,9 \& 5$ days during 1996, 1997 \& 1998, respectively) and recorded all gazelles seen: most sightings (92 per cent, $n=195$ ) were between 0900 and $1400 \mathrm{~h}$, and each year included both summer and winter visits.

\section{Results}

\section{Distribution of gazelles within the reserve}

During October 1998-February 1999, gazelles were observed in the Matham wadi system only, and most were in the fenced Ghaba section of it. Nevertheless, there were recent signs of gazelles in lower unfenced Matham and in wadis Bordan, Rahal and Naam, and on better-vegetated parts of the plateau (Fig. 1b). The total geographical range of the population (a minimum-area convex polygon around all locations of gazelle signs or sightings) was $890 \mathrm{sq} \mathrm{km}$, but gazelles resided in a small proportion of this range.

\section{Status of gazelles in the Matham wadi system}

One tagged female was observed in fenced wadi Ghaba twice during October-November 1998 and a second during December. The minimum number of gazelles here was 26 ( 7 adult males, 8 adult females, 2 yearling males, 2 large-juvenile males, 7 juveniles), which represented a 41 per cent decline since 1994 (Table 1). This was similar to the 53 per cent decline between 1994 and 1998 in the mean number of gazelles seen daily. An apparent decrease between 1996 and 1998 in the number of gazelles along a $4-\mathrm{km}$ drive in this wadi was not significant (Fig. 2). In fenced Ghafar, the minimum number of gazelles was five ( 1 adult male, 2 adult females, 2 juveniles) during 1998, a 67 per cent decline since 1994, while the mean number seen daily declined by 75 per cent (Table 1 ).

No tagged gazelles were seen in unfenced Matham during October-November 1998, but one tagged female was sighted during December. The minimum number of gazelles here was six ( 2 adult males, 2 adult females, 1 large-juvenile male, 1 juvenile), which represented an 89 per cent decline since 1994 (Table 1). This was similar to the 94 per cent decline in the average number of 
Table 1 Numbers of mountain gazelles seen in fenced wadis Ghaba and Ghafar and unfenced wadi Matham during October-November of 1994 and 1998. Mark-recapture estimates for 1994 are from Dunham (1997), but no estimate was available for Ghafar. CL $=95$ per cent confidence limit; $\mathrm{SD}=$ standard deviation.

\begin{tabular}{|c|c|c|}
\hline & \multicolumn{2}{|l|}{ Study period } \\
\hline & October-November 1994 & October-November 1998 \\
\hline Number of days visited $(n)$ & 12 & 7 \\
\hline \multicolumn{3}{|l|}{ Fenced wadi Ghaba } \\
\hline Mean number of gazelles seen daily ${ }^{a}$ & $23.4($ SD 5.9) & $11.0(\mathrm{SD} 3.9)$ \\
\hline Mean number of tagged gazelles seen daily & $4.3(\mathrm{SD} 1.7)$ & $0.3(\mathrm{SD} 0.5)$ \\
\hline Number of tagged gazelles in wadi & 9 & 2 \\
\hline Minimum number of gazelles in wadi & 44 & 26 \\
\hline Mark-recapture estimate of total number & 48 (CL 40 \& 58) & - \\
\hline \multicolumn{3}{|l|}{ Fenced wadi Ghafar } \\
\hline Mean number of gazelles seen daily ${ }^{b}$ & $5.3(\mathrm{SD} 2.0)$ & $1.3(\mathrm{SD} 1.9)$ \\
\hline Mean number of tagged gazelles seen daily & $2.3(\mathrm{SD} 1.0)$ & 0 \\
\hline Number of tagged gazelles in wadi & 8 & 0 \\
\hline Minimum number of gazelles in wadi & 15 & 5 \\
\hline \multicolumn{3}{|l|}{ Unfenced wadi Matham } \\
\hline Mean number of gazelles seen daily ${ }^{c}$ & 20.7 (SD 8.4) & $1.3(\mathrm{SD} 1.8)$ \\
\hline Mean number of tagged gazelles seen daily & $3.9(\mathrm{SD} 1.8)^{d}$ & 0 \\
\hline Number of tagged gazelles in wadi & $10+1$ radiocollared & 1 \\
\hline Minimum number of gazelles in wadi & 54 & 6 \\
\hline Mark-recapture estimate of total number & 57 (CL 48 \& 71) & - \\
\hline
\end{tabular}

${ }^{a} 1994$ vs. 1998 , Student's $t$-test, $t_{17}=4.96, P<0.001$.

${ }^{b} 1994$ vs. 1998 , Student's $t$-test, $t_{17}=4.30, P<0.001$.

${ }^{c} 1994$ vs. 1998, Mann-Whitney rank sum test, $T=28, n_{1}=7, n_{2}=12, P<0.001$.

${ }^{d}$ Excluding one gazelle with a functioning radiocollar.
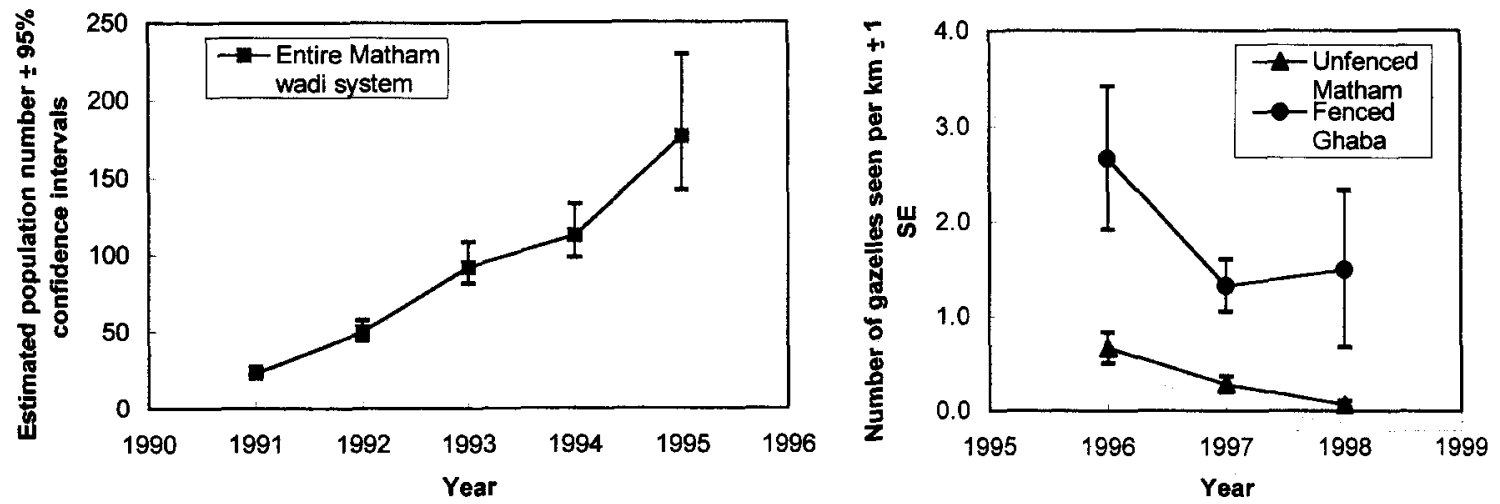

Fig. 2 Changes in the number of mountain gazelles in the Matham wadi system: mean estimated population number, with 95 per cent confidence intervals, during June of 1991-95 for the entire Matham wadi system (fenced and unfenced wadis) (data from Dunham [1997]); the mean number ( \pm 1 standard error) of gazelles seen per $\mathrm{km}$ while driving standard routes through unfenced wadi Matham and fenced wadi Ghaba during 1996-98. Both these wadis form part of the Matham wadi system. Data for 1996 were collected before the first-known poaching incident in November 1996. The decline was significant in unfenced Matham (one-way analysis of variance, $F_{2,17}=6.69, P=0.011$ ), but not in fenced Ghaba $\left(F_{2,17}=1.63, P=0.2\right)$.

gazelles seen daily. The mean number seen along a 17-km drive here declined by 89 per cent during 199698 (Fig. 2), with a decrease occurring from 1996 to 1997 (Student-Newman-Keuls pairwise comparison, $P<0.05)$, but not from 1997 to $1998(P>0.05)$.

The minimum number of gazelles in the entire Matham system (fenced and unfenced) during
October-November 1998 was 37 (10 adult males, 12 adult females, 10 juveniles, 5 large-juvenile or yearling males). This represents a 64 per cent decline from a minimum of 103 during October-November 1994. Of 23 tagged gazelles in the entire Matham system at the time when intensive monitoring ceased, six were never observed again and three were seen during the 1998 
survey. Of 14 last observed between July 1995 and November 1997, 10 were last seen during the 4-month period from October 1996-January 1997, although regular visits were made after that time (Fig. 3).

\section{Gazelle sex/age ratios and group composition}

The observed adult sex ratio was 0.7-0.8 males per female during 1994-97, but doubled to $1.5: 1$ during 1998-99 (Table 2). Similarly, the observed ratio of juveniles $<6$ months old to females was constant at 0.9-1 : 1 during 1994-97, but increased to $1.5: 1$ during 1998-99 (Table 2). When only October-November 1998 data were considered, the ratios were high amongst the observed animals ( 1.4 adult males and 1.2 juveniles per adult female); but within the minimum population, the ratios ( 0.83 adult males and 0.83 juveniles per female) were similar to those amongst observed animals during earlier years.

The frequency of occurrence during 1998-99 of each social grouping did not differ significantly from the grouping's mean occurrence during 1994-97 (Table 3). But the frequency during 1998-99 of five of the six principal groupings was outside the range of values observed during the previous 4 years. Mean group size during October 1998-February 1999 was 2.1 (range 1-8, $n=124$ ), the same as during 1994 (mean 2.1, range 1-10 [Dunham, 1999]).

\section{Flight behaviour of gazelles}

Fourteen of 15 gazelle groups seen in unfenced Matham during October 1998-February 1999 were observed in

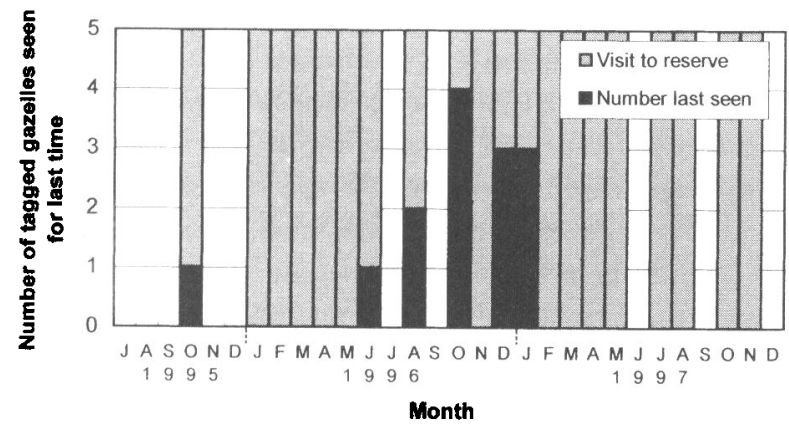

Fig. 3 Months in which the Matham wadi system was visited, from the end of intensive monitoring during June 1995 until December 1997; and the number of tagged mountain gazelles (known to be alive in the Matham wadi system during June 1995) that were seen for the last time during each month. A new fence built by reserve management was destroyed immediately by local people during May 1996 and the first gazelle known to be poached was found during November 1996. The water troughs were stolen during January 1997 and dam construction in unfenced lower Matham commenced during December 1997. A herd of domestic sheep/ goats was taken into this wadi system during 1998.
Table 2 Changes in the observed adult sex ratio and the observed juvenile:female ratio within the population of mountain gazelles. Many observations were repeat sightings of the same individuals. Data for 1994 are from Dunham (1999).

\begin{tabular}{llll}
\hline & $\begin{array}{l}\text { Number of } \\
\text { gazelles } \\
\text { classified }\end{array}$ & $\begin{array}{l}\text { Number of } \\
\text { adult males } \\
\text { per adult } \\
\text { female }\end{array}$ & $\begin{array}{l}\text { Number of } \\
\text { juveniles } \\
<6 \text { months old } \\
\text { per adult female }\end{array}$ \\
\hline Study period & 4115 & 0.66 & 0.86 \\
1994 & 1242 & 0.67 & 0.87 \\
1995 & 353 & 0.81 & 0.97 \\
1996 & 186 & 0.75 & 0.89 \\
1997 & 264 & 1.53 & 1.48 \\
$\begin{array}{l}\text { October 1998- } \\
\text { February 1999 }\end{array}$ & & & \\
\hline
\end{tabular}

${ }^{a}$ Mean number of adult males per adult female during 1994$97=0.723($ SD $0.071, n=4)$. Ratio for 1998-99 differed significantly (comparison of single observation with sample mean [Sokal \& Rohlf, 1981l, $t_{3}=10.16, P<0.01$ ).

${ }^{b}$ Mean number of juveniles per adult female during 1994-97 $=0.898$ $(\mathrm{SD} 0.050, n=4)$. Ratio for $1998-99$ differed significantly $\left[t_{3}=10.41\right.$, $P<0.01]$

the morning and only one group was seen in the afternoon. Seven groups ran up the steep wadi sides when disturbed, while four others ran off and may have climbed the slopes when out of my sight. Comparable data for 1994 are not available, but in that year it was unusual for gazelles seen here to run up the wadi sides when disturbed. In contrast, no change in gazelle flight behaviour was observed in fenced Ghaba during 199899, compared with 1994.

\section{Distribution of domestic and feral animals}

Camels occurred throughout the reserve, but were concentrated in wadis. They had temporary access to fenced wadis when this survey started, but later were excluded from Ghaba and Ghafar. Sheep/goats occurred in most wadis and totalled c. 1100 animals. There was little overlap between their distribution and that of gazelles (Fig. 1b). Overlap occurred in two places: close to some houses in wadi Bordan, and in unfenced Matham, which sheep/goats entered shortly before this survey. Some sheep/goat herds lived in the reserve, while others foraged there during the day, but were enclosed in pens on the periphery at night. A feral dog was seen in unfenced Matham, and footprints at three sites near the reserve boundary were probably those of dogs. I am uncertain, however, which large canid left prints in wadi Bordan because I have never seen dogs in that area. Some dogs were not feral: a collared dog was seen near a goat herd in wadi Matham. 
Table 3 The composition of all mountain gazelle groups seen in the entire Matham wadi system (fenced and unfenced wadis) during October 1998-February 1999, compared with earlier years (1994 data from Dunham [1999]). Figures are the percentages of all groups seen during each period that had different compositions. $n=$ number of groups seen (excluding groups that included some individuals not classified to age and sex), but many observations were repeat sightings of the same individuals. Bachelor males were defined as solitary large-juvenile or yearling males, or groups that contained any combination of large juvenile, yearling or adult males. For each social grouping, the percentage for 1998-99 was compared with the mean percentage for 1994-97, using a $t$-test on the arc-transformed percentages (degrees of freedom $=3$; not significant in all cases).

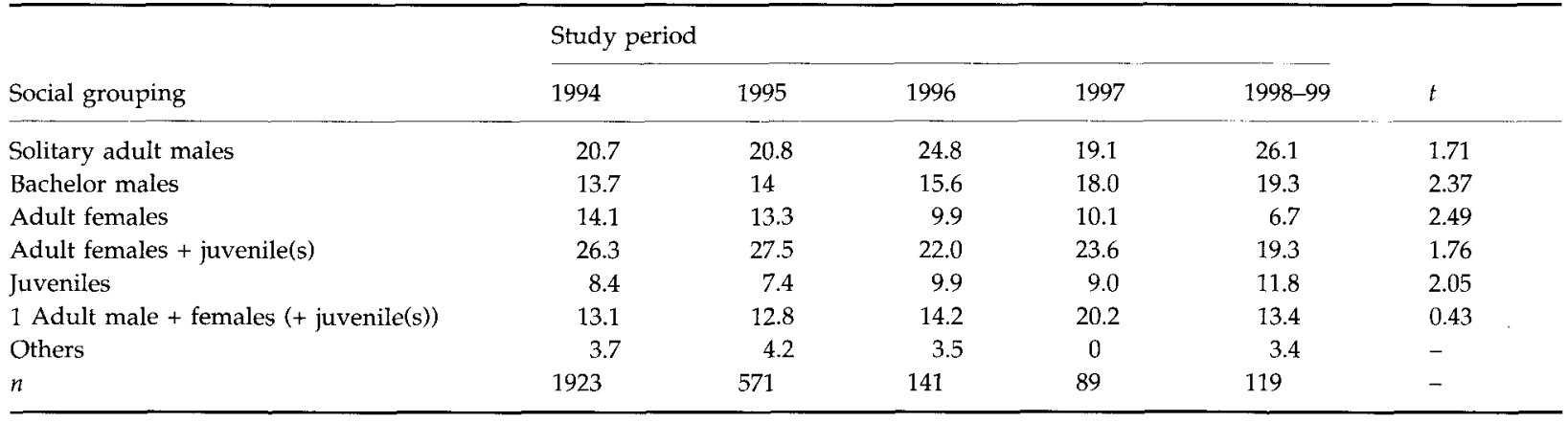

\section{Discussion}

\section{Status of the reintroduced population}

Sightings of gazelles decreased during 1994-98 by 90 per cent in unfenced Matham, by 70 per cent in fenced Ghafar, and by $40-50$ per cent in fenced Ghaba. The Matham decline occurred mainly from 1996 to 1997, coinciding with the disappearance of tagged gazelles. Recent signs of gazelles were common in unfenced Matham, although few animals were seen there. This, and the animals' tendency to flee, suggested that gazelles fed there at night, retreating to the hills during daytime. This would represent a change in gazelle behaviour since 1994 and is the behaviour often shown by hunted ungulates (Kilgo et al., 1998). One consequence of the behavioural changes is that daytime sightings no longer reliably measure gazelle abundance. Gazelle numbers were difficult to estimate, particularly where signs, but not animals, were seen. Signs were not formally recorded previously and even indices of population trends are unavailable for areas where no animals were seen. Outside the Matham system, signs were concentrated in four areas, but their relative frequency, cf. unfenced Matham, suggested that gazelle densities were low. Middens on the plateau provided the first evidence that gazelles resided there. Rainfall was above average in three winters during 1994-98. After seasons of below-average rainfall, there may not be sufficient food year-round for gazelles on the plateau.

\section{Factors potentially influencing gazelle numbers}

\section{Domestic livestock}

Previously, gazelles lived alongside camels in unfenced Matham (Dunham, 1997). The greater plant biomass and greater gazelle density in fenced Ghaba suggested that camels reduced food availability for gazelles; but gazelle density in Matham increased, despite the camels' presence, suggesting that competition for food between camels and gazelles was not severe enough to eliminate gazelles. There are several possible reasons why signs of sheep/goats and gazelles seldom overlapped. Perhaps large domestic flocks obliterated gazelle signs (although it is unlikely that droppings would disappear), or maybe shepherds frightened the gazelles (but gazelles could still have visited, at night, areas used diurnally by sheep/goats). It is most likely that sheep and goats selected similar food items to gazelles and, being more numerous, ate so much of the plant biomass that the food supply for gazelles was severely depleted. Nonetheless, sheep/goats did not cause the decline in gazelle numbers in unfenced wadi Matham, most of which was empty of sheep or goats.

\section{Feral dogs}

Dogs were seen during 1998-99 in a wadi where the frequency of gazelle sightings declined. Predation might have contributed to this decrease, but the rangers have not reported any gazelles killed by dogs since 1994 .

\section{Dam building}

Fresh signs of gazelles near Matham dam suggested that its construction did not cause the decline in gazelle numbers. Furthermore, building commenced during December 1997, after the decline started. Nonetheless, disturbance may have prompted gazelles to be less active diurnally.

\section{Removal of water troughs}

Artificial water supplies were not essential for gazelle survival after the immediate post-release period 
(Dunham, 1998b) and it is unlikely that theft of the water troughs from wadis Ghaba and Ghafar during January 1997 caused gazelle numbers to decline.

\section{Illegal hunting}

Poaching was first detected during November 1996, when rangers recovered a shot gazelle. This coincided with the 1996-97 decline in gazelle sightings and the disappearance of tagged animals, suggesting that poaching may have caused both. From indirect evidence, e.g. finding people with firearms, the rangers believed that poaching continued through 1998 (although many Saudis own firearms and mere possession is not proof of poaching). No direct evidence of poaching was found, although the change in gazelle flight behaviour in unfenced Matham was consistent with the population having been severely disturbed. The decline in gazelle sightings probably reflected a combination of the following: increased mortality as a direct result of poaching; reduced daytime use of wadis by the survivors and an increase in their flight distance; and, possibly, the movement of some individuals to other parts of the reserve. Poaching was probably precipitated by the decision - taken without adequately consulting with local people - during May 1996 to build a new fence across wadi Matham. This new fence was destroyed, the Ghaba and Ghafar fences (previously tolerated) damaged, and the troughs stolen. These were probably acts of defiance directed at the reserve's management.

\section{Implications for conservation}

\section{Monitoring of reintroduced populations}

The need for long-term monitoring of reintroduced populations is emphasized. Intensive monitoring ceased mainly because of financial constraints, but the reintroduction's initial success had also encouraged some people to believe that monitoring was no longer needed. Ranger patrol reports were considered as a long-term means of monitoring gazelle numbers, but preliminary analysis revealed that report quality must be improved first, by increasing ranger training. However, for reasons discussed, it will now be difficult to monitor gazelle numbers using only daytime sightings of animals.

\section{Adverse effects of domestic livestock}

NCWCD protected areas are essentially non-hunting reserves, without legal restrictions on domestic livestock, although management authorities may try to negotiate limitations with the local people. The avoidance, by gazelles at Hawtah, of areas used by sheep/ goats has important implications for reserve manage- ment. It emphasizes the need to exclude sheep/goats from the Matham wadi system, because gazelles had thrived here and this is the only wadi system that was free of sheep/goats until recently. Secondly, sheep/ goats (under current management) will severely limit gazelle numbers and distribution. Numbers of sheep/ goats would be reduced if they were managed in the traditional manner as practised until a few decades ago: traditional management did not include the current practices of providing grain as supplementary food, or of transporting water to flocks.

\section{Law enforcement}

The legal system for protecting gazelles in the reserve failed, even though gazelle hunting had been illegal for years. The rangers have no legal powers of search or arrest, and indicated that they were not fully supported by local police and civic authorities, who were responsible for arrests and prosecutions. Consequently, the rangers' morale was low. The difficulties of wildlife protection in Saudi Arabia were recognized previously (Thouless, 1991) and are not confined to Hawtah: gazelle poaching has occurred in Al-Khunfah and Uruq Bani Ma'arid protected areas (Wacher, 1997; Ostrowski et al., 1998). Effective protection of wildlife will depend on the NCWCD receiving support at the highest levels of government.

\section{Relations with local people}

The reaction of local people to the new fence emphasizes the need for the management authorities to establish a dialogue with local people and to involve them in deciding management policies. Unfortunately, recent attempts at this have been hampered by disputes amongst the local people.

\section{Conclusion}

The problems faced by the reintroduced population discussed here are not unique. These lessons apply throughout the Middle East and North Africa, where persecution by humans has eliminated much wildlife, grazing by domestic livestock is common, and reserves are new or absent. There are some differences between the gazelle poaching and the poaching of Oman's Arabian oryx Oryx leucoryx (e.g. oryx were captured for sale abroad [Spalton et al., 1999]), but there are also parallels. Both reintroductions involved the release of captive-bred animals into new reserves, to replace populations eliminated by excessive hunting, and were initially successful. Ranger teams included local people (Stanley Price, 1989), but when severely challenged by their fellow citizens, neither team could successfully enforce their country's wildlife protection laws. 


\section{Acknowledgements}

I thank the NCWCD rangers for their help over many years, while they undertook a difficult and often thankless task. I hope that this paper highlights their problems and does not add to them. I thank Fay Robertson for comments on an earlier draft. The study was funded by the NCWCD.

\section{References}

Cano, M., Abaigar, T. \& Vericad, J.R. (1993) Establishment of a group of dama gazelles for reintroduction in Senegal. International Zoo Yearbook, 32, 98-107.

Cloudsley-Thompson, J.L. (1992) Wildlife massacres in Sudan. Oryx, 26, 202-204.

Dunham, K.M. (1997) Population growth of mountain gazelles Gazella gazella reintroduced to central Arabia. Biological Conservation, 81, 205-214.

Dunham, K.M. (1998a) Spatial organization of mountain gazelles Gazella gazella reintroduced to central Arabia. Journal of Zoology (London), 245, 371-384.

Dunham, K.M. (1998b) Use of artificial water supplies by captive-born mountain gazelles Gazella gazella released in central Arabia. Journal of Zoology (London), 246, 449-454.

Dunham, K.M. (1998c) The release of captive-bred animals to reintroduce mountain gazelles Gazella gazella to central Arabia. In Proceedings of the Seminar on the Conservation and Restoration of Sahelo-Saharan Antelopes. Djerba, Tunisia (ed. UNEP/CMS), pp. 123-130. CMS Technical Series Publication no. 3. UNEP/CMS Secretariat, Bonn, Germany.

Dunham, K.M. (1999) Social organisation of mountain gazelles Gazella gazella in a population reintroduced to central Arabia. Journal of Arid Environments, 43, 251-266.

Dunham, K.M., Kichenside, T.B., Lindsay, N., Rietkerk, F. \& Williamson, D.T. (1993) The reintroduction of mountain gazelle Gazella gazella in Saudi Arabia. International Zoo Yearbook, 32, 107-116.
Kilgo, J.C., Labisky, R.F. \& Fritzen, D.E. (1998) Influences of hunting on the behaviour of white-tailed deer: implications for conservation of the Florida panther. Conservation Biology, 12, 1359-1364.

Newby, J.E. (1990) The slaughter of Sahelian wildlife by Arab royalty. Oryx, 24, 6-8.

Ostrowski, S., Bedin, E., Lenain, D.M. \& Abuzinada, A.H. (1998) Ten years of Arabian oryx conservation breeding in Saudi Arabia - achievements and regional perspectives. Ory $x, 32$, 209-222.

Sokal, R.R. \& Rohlf, F.J. (1981) Biometry. W.H. Freeman, San Francisco.

Spalton, J.A., Lawrence, M.W. \& Brend, S.A. (1999) Arabian oryx reintroduction in Oman: successes and setbacks. Oryx, 33, 168-175.

Stanley Price, M.R. (1989) Animal Re-Introductions: the Arabian Oryx in Oman. Cambridge University Press, Cambridge:

Thesiger, W. (1959) Arabian Sands. Longman, London.

Thouless, C. (1991) Conservation in Saudi Arabia. Oryx, 25, 222-228.

Wacher, T. (1997) Uruq Bani Ma'arid. In King Khalid Wildlife Research Centre Report for May and June 1997, pp. 15-18. Unpublished Report, KKWRC, Thumamah, Saudi Arabia.

\section{Biographical sketch}

After graduating from the University of Bristol, Kevin Dunham studied impala for a master's degree at the (then) University of Rhodesia. He then spent almost 10 years living on the banks of the Zambezi River, where he researched the ecology of Acacia albida riverine woodlands. A complete change of ecosystem followed, when he monitored reintroduced gazelle populations in Arabia. He is now back in Africa where he spends a lot of time thinking about declining populations of tsessebe antelope. 